\title{
The Role of Digital Navigators in Promoting Clinical Care and Technology Integration into Practice
}

\author{
Hannah Wisniewski ${ }^{a}$ Tristan Gorrindo ${ }^{c} \quad$ Natali Rauseo-Ricupero ${ }^{a}$ \\ Don Hilty ${ }^{b}$ John Torous ${ }^{a}$ \\ aDivision of Digital Psychiatry, Beth Israel Deaconess Medical Center, Boston, MA, \\ USA; ${ }^{b}$ Department of Psychiatry and Behavioral Sciences, Northern California Veterans \\ Administration Health Care System, University of California Davis, Mather, CA, USA; \\ ${ }^{c}$ American Psychiatric Association, Washington, DC, USA
}

\section{Keywords}

mHealth · Digital health · Apps · Health

\section{Abstract}

As the role of technology expands in healthcare, so does the need to support its implementation and integration into the clinic. The concept of a new team member, the digital navigator, able to assume this role is introduced as a solution. With a digital navigator, any clinic today can take advantage of digital health and smartphone tools to augment and expand existing telehealth and face to face care. The role of a digital navigator is suitable as an entry level healthcare role, additional training for an experienced clinician, and well suited to peer specialists. To facilitate the training of digital navigators, we draw upon our experience in creating the role and across health education to introduce a 10-h curriculum designed to train digital navigators across 5 domains: (1) core smartphone skills, (2) basic technology troubleshooting, (3) app evaluation, (4) clinical terminology and data, and (5) engagement techniques. This paper outlines the curricular content, skills, and modules for this training and features a rich online supplementary Appendix with step by step instructions and resources.

\section{Introduction}

As interest in telehealth and digital health expands, more clinics are seeking to integrate technology into practice. The COVID-19 pandemic has only accelerated this interest [1]. A surge in telehealth use has also expanded the need for digital health to bring new remote data 
into visits and augment treatment between appointments. From simple smartphone surveys to complex digital measures, novel wearables to online therapies - the potential of new technology informed tools is growing across healthcare. To harness this potential, we note the need for a new member of the healthcare team called a digital navigator who, among other duties, can utilize evidence-based tools to evaluate and select apps, support the digital therapeutic alliance by helping patients customize and troubleshoot technology, and facilitate care by ensuring data quality [2]. In this paper we propose a training curriculum for the digital navigator role and explore the knowledge, skills, and competencies necessary to undertake this position.

Even before COVID-19, this interest in digital health spurred many clinics to implement digital care tools without a well-constructed implementation plan or considerations for staffing and policies necessary for successful roll-out [3]. Learning from past experience that offering technology solutions alone often results in unsuccessful implementation efforts [4], it is clear there must be a focus on training and supporting frontline providers as well as new auxiliary staff who can support digital health. Indeed, the need for training and support is still noted as primary barriers for community health clinics offering telehealth and technology services [5]. Recent research across diverse medical specialties suggests the most common barrier to successful use of technology in care is not the technology itself, but rather these workflow issues related to training [6, 7]. This has been true for video, digital health, social media, and other asynchronous technologies [8].

Yet training for clinical staff around digital technology, especially digital health and smartphone apps, for care remains limited. This lack of training opportunities has been directly linked to lower uptake and acceptance of digital health technologies by clinicians [9]. It has also limited the use of digital health technologies in low- and middle-income countries where training is identified as a primary barrier [10] to global adoption. These countries are primed to use digital health to increase access to and quality of care in a scalable and low-cost manner, but training of clinicians and end-users is "frequently neglected" and contributes to low rates of clinic adoption [11]. Digital health has expanded rapidly in some fields like mental health where competencies have been published for telepsychiatry/video, social media, and digital health [12-14]. Unfortunately, organizational change is slow in adopting these competencies because of complex policy, medico-legal, and regulatory environments [15]. The COVID-19 pandemic, though, has required that all clinicians adopt these tools and has bypassed the usual roadblocks to system change in order to ensure patients continued to receive treatment. For example, in exploring how the field can ensure there is not a rise in deaths by suicide, one group of authors noted "digital training resources would enable those who have not previously worked with people who are suicidal to take active roles in health services and helpline" [16] - highlighting the need for rapid training to allow staff to take on new urgent clinical roles. The need for such training and support is broad and also exists in diabetes [17], cardiovascular disease [18], neurology [19], and psychiatry among many other specialties.

As healthcare technologies evolve, so must the training to support them. Behind even well-designed technologies there must be competencies, training, and technical assistance to support clinicians and patients. Prior to the COVID pandemic, new technologies would commonly be introduced to clinicians by designating a "clinician champion" and a teaching faculty. Working together they would develop and "implement clinical competencies to steer training and faculty development" [20]. However, we have seen in the COVID era that the process of establishing competencies and then implementing training is not sufficient to address the rapid pace of technology change, and we therefore present a new model to support successful implementation of digital health technologies.

We have proposed the role of the "digital navigator" previously - as a new team member able to help facilitate and implement technology into care [21]. Here, we outline the skills, 
knowledge, and competencies needed to become a digital navigator. The potential for this role is broad and the position may be ideal as an entry healthcare team member role, but systems need flexibility. The person may be an established clinician, medical assistant, nurse case manager, peer specialist, member of the office staff, or other who now gains specific expertise in digital health and serves in the role of digital navigator. The content presented in the training below is derived from preliminary experience training digital navigators and working with them in clinical settings for over 1 year. We propose a 10-h training and certification process as a means to offer concrete and actionable next steps for advancing this role, but recognize that it may need to be adapted with content added for unique clinical needs, specific technology use cases, and new digital biomarkers [22]. The broad nature of this training aims to make it a foundation for use in all healthcare fields, ranging from, for example, psychiatry and neurology [23] to surgery [24] and dermatology [25].

The goal of the certification process is to define the role and skills of a digital navigator to support clinical teams by offering front-line technical assistance in the integration of clinical, technical, workflow, and administrative factors that pertain to the implementation of digital health technology. Effectiveness and implementation science factors (e.g., adoptability, feasibility, sustainability) inform this approach to the position. While this paper does not address the important question of how certification is maintained, it presents a concrete outline for training that is supported by popular concepts in the field but differs through offering hands on and tangible next steps. We do not discuss the cost-effectiveness of such training, but propose that resulting increases in digital health adoption and engagement could in theory offer a financial motivation for implementing digital navigators.

Teaching skills/competencies successfully will likely require a mixture of methods that can be layered and adjusted for increasing the skill level over time, and which incorporate evaluation methods that can determine that competencies have been achieved and can provide formative feedback to the learners [26]. As those in different countries adopt the training and role of the digital navigator to best serve their clinics, new methods and modules will be necessary. Combining these into an online library of educational resources is an underlying goal of this effort.

\section{Curricular Content: Skills and Modules}

Regardless of the navigator's background experience and skills, the 3 core responsibilities are: (1) selecting apps, (2) troubleshooting technology, and (3) reviewing and quality checking digital data to facilitate care [27]. Much like a radiology or pathology technologist became an essential role as each of these fields developed new imaging and lab tests, so must the rest of medicine adopt individuals on the care team to support digital health. While the digital navigator role and training is not designed to develop medical thinking or decision making, the core skills and competencies it offers could augment the acumen of an experienced clinician, facilitate workflow, and bring a valuable skillset to the interprofessional team. Likewise, the role and training could also support a new member of the care team who could support multiple clinicians and an entire team/clinic.

The initial training presented below teaches the basic knowledge and skills necessary for the digital navigator role using a competency-based approach. This training for the digital navigator role consists of 5 main modules: (1) core smartphone skills, (2) basic technology troubleshooting, (3) app evaluation, (4) clinical terminology and data, and (5) engagement techniques. Each module builds upon the previous and successful completion is necessary to advance to the next. Upon completion of all 5 modules, an individual will have the foundational skills required to be a digital navigator. 


\section{Digital Biomarkers}

\begin{tabular}{|c|c|c|c|c|}
\hline \multicolumn{5}{|c|}{ MODULES } \\
\hline Core Smartphone Skills & Basic Technology Troubleshooting & App Evaluation & Clinical Terminology and Data & Engagement Techniques \\
\hline \multicolumn{5}{|c|}{ Objectives } \\
\hline $\begin{array}{l}\text { 1. Obtain a basic understanding of } \\
\text { how to use smartphone tools } \\
\text { 2. Be able to independently utilize } \\
\text { smartphone tools to benefit mental } \\
\text { health. }\end{array}$ & $\begin{array}{l}\text { 1. Learn about common } \\
\text { troubleshooting problems } \\
\text { 2. Demonstrate effective methods to } \\
\text { solve basic troubleshooting issues }\end{array}$ & $\begin{array}{l}\text { 1. Learn to evaluate apps } \\
\text { independently } \\
\text { 2. Learn how to use an app evaluation } \\
\text { tool to recommend clinically } \\
\text { appropriate apps }\end{array}$ & $\begin{array}{l}\text { 1. Obtain a basic understanding of } \\
\text { clinical terminology } \\
\text { 2. Demonstrate ability to summarize } \\
\text { potentially clinically relevant } \\
\text { information from graphs and app data }\end{array}$ & 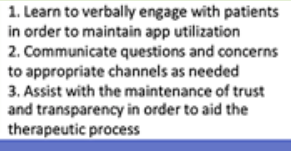 \\
\hline \multicolumn{5}{|c|}{ Tools: curriculum requirements within each module } \\
\hline $\begin{array}{ll}\text { 1. Wifi and data } & \text { 8. Clock } \\
\text { 2. Calls } & \text { 9. Calendar } \\
\text { 3. Text messaging } & \text { 10. Health Apps } \\
\text { 4. Internet } & \\
\text { 5. Music } & \\
\text { 6. Photos \& videos } & \\
\text { 7. Notes \& reminders }\end{array}$ & $\begin{array}{ll}\text { 1. Complications } & \text { 4. App compatibility } \\
\text { downloading an } & \text { issues } \\
\text { app } & \text { 5. Wifi/data } \\
\text { 2. Unknown } & \text { connection } \\
\text { account } & \text { 6. Notification issues } \\
\text { ID/password } & \text { 7. App crashing } \\
\text { 3. Lack of storage } & \text { 8. Bluetooth } \\
\text { space } & \text { connections }\end{array}$ & $\begin{array}{l}\text { 1. Gather background } \\
\text { information } \\
\text { 2. Risk/Privacy \& } \\
\text { Security } \\
\text { 3. Evidence } \\
\text { 4. Ease of Use } \\
\text { 5. Interoperability }\end{array}$ & $\begin{array}{l}\text { 1. Diagnoses } \\
\text { 2. Clinical Red Flags } \\
\text { 3. HIPAA Compliance } \\
\text { and confidentiality } \\
\text { 4. Types of Data } \\
\text { Streams }\end{array}$ & $\begin{array}{l}\text { 1. Interviewing } \\
\text { methods } \\
\text { 2. Communication } \\
\text { Methods } \\
\text { 3. Convening Trust } \\
\text { and transparency }\end{array}$ \\
\hline \multicolumn{5}{|c|}{ Skills: knowledge required to complete a tool } \\
\hline 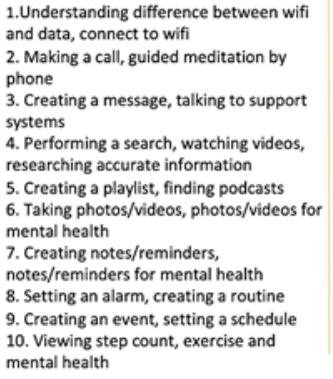 & $\begin{array}{l}\text { 1. Checking connections, deleting } \\
\text { apps } \\
\text { 2. Recovering passwords } \\
\text { 3. Deleting apps, download size } \\
\text { 4. Updating software } \\
\text { 5. Switching networks, checking } \\
\text { network strength, changing locations } \\
\text { 6. Updating notification settings } \\
\text { 7. Closing and reopening apps } \\
\text { 8. Updating apps, } \\
\text { disconnecting//oonnecting to } \\
\text { Bluetooth, resetting wearables }\end{array}$ & $\begin{array}{l}\text { 1. App costs, developer, platforms, } \\
\text { last update, reviews } \\
\text { 2. Privacy policy, data collection, opt- } \\
\text { out, deleting data, data sharing, } \\
\text { HIPAA-compliance } \\
\text { 3. What does the app do?, peer- } \\
\text { reviewed evidence, red flags } \\
\text { 4. Customizability, accessibility, easy } \\
\text { to use } \\
\text { 5. Data sharing, } \\
\text { exporting/downloading data, } \\
\text { integration with other platforms }\end{array}$ & $\begin{array}{l}\text { 1. Depressive Disorders, } \\
\text { Anxiety Disorders } \\
\text { 2. Warning signs, When to seek } \\
\text { help } \\
\text { 3. Adhering to HIPAA } \\
\text { regulations, Understanding and } \\
\text { practicing program specific } \\
\text { compliancy and confidentiality } \\
\text { protocols } \\
\text { 4. Active Data, Passive Data }\end{array}$ & $\begin{array}{l}\text { 1. Asking for clarification, open } \\
\text { ended questions } \\
\text { 2. Refer patient to appropriate } \\
\text { sources } \\
\text { 3. Acknowledge role limitations } \\
\text { which conveys honesty and } \\
\text { trust }\end{array}$ \\
\hline
\end{tabular}

Fig. 1. A summary of the training content broken down by the objectives, tools, and skills for each module.

Each module of the training (Fig. 1) is organized into corresponding objectives, tools, and skills. Objectives list the learning goals for that module. The tools within a given module are the broad categories of understanding required to complete the module and meet the learning objectives. For example, in the "Core Smartphone Skills" module, the tools are the general tasks a digital navigator would be required to perform on their smartphone, such as browsing the internet or sending a text message. Tools will then be broken down into skills. Skills are the specific competencies required to be proficient in a tool. For example, if the tool is sending a text message, the skills would be creating a new message, responding to a message, sending pictures and videos, and sending messages to a group. Finally, each skill is broken into steps (not shown in Fig. 1), which offer specific details on how to complete that particular skill. Steps for each tool and skill can be found in the online supplementary Appendix (for all online suppl. material, see www.karger.com/doi/10.1159/000510144). The Appendix offers examples of skills and steps that we have found useful in training digital navigators, and that others may want to add to in order to meet specific needs.

The training is designed to be completed in the order shown in Figure 1 beginning with "core smartphone skills" and progress will be assessed after each module. As the digital navigator trainee moves throughout the modules, he/she will notice the previously learned tools and tasks built upon earlier ones now mastered. Trainees will be required to demonstrate their knowledge of each module before continuing with training. Assessments will be conducted via simulation of common clinical scenarios. The trainee will be scored in 3 broad categories for all modules: (1) assessment, (2) solution, and (3) communication. Scoring details are provided in Table 1. Further details on the objectives, tasks, skills, and assessment for each module are provided below. 
Table 1. Scoring

\begin{tabular}{|c|c|c|c|}
\hline \multirow[t]{2}{*}{ Score metric } & \multicolumn{3}{|l|}{ Rubric } \\
\hline & 1 & 2 & 3 \\
\hline $\begin{array}{l}\text { Assessment } \\
\text { The trainee will be required to } \\
\text { demonstrate that they are able to } \\
\text { assess the presented problem }\end{array}$ & $\begin{array}{l}\text { Trainee was unable to } \\
\text { correctly assess the } \\
\text { presented problem }\end{array}$ & $\begin{array}{l}\text { Trainee was able to correctly } \\
\text { assess parts of the presented } \\
\text { problem, but not all }\end{array}$ & $\begin{array}{l}\text { Trainee was able to } \\
\text { correctly assess all parts } \\
\text { of the presented problem }\end{array}$ \\
\hline $\begin{array}{l}\text { Solution } \\
\text { The trainee will need to demonstrate } \\
\text { that they are able to provide a } \\
\text { solution to the problem }\end{array}$ & $\begin{array}{l}\text { Trainee was unable to } \\
\text { provide a solution to the } \\
\text { problem }\end{array}$ & $\begin{array}{l}\text { Trainee was able to provide a } \\
\text { sufficient solution to the } \\
\text { problem, but was unable to } \\
\text { perform the required steps }\end{array}$ & $\begin{array}{l}\text { Trainee was able to provide } \\
\text { a sufficient solution to the } \\
\text { problem, and perform the } \\
\text { required steps }\end{array}$ \\
\hline $\begin{array}{l}\text { Communication } \\
\text { The trainee must demonstrate they } \\
\text { are able to communicate the problem } \\
\text { to the clinician and/or patient } \\
\text { efficiently and appropriately }\end{array}$ & $\begin{array}{l}\text { Trainee was unable to } \\
\text { communicate their } \\
\text { solution }\end{array}$ & $\begin{array}{l}\text { Trainee was able to } \\
\text { communicate their solution, } \\
\text { but with a poor or } \\
\text { inappropriate manner }\end{array}$ & $\begin{array}{l}\text { Trainee was able to } \\
\text { communicate their solution } \\
\text { to the problem in a sufficient } \\
\text { manner }\end{array}$ \\
\hline
\end{tabular}

\section{Module 1: Core Smartphone Skills}

The core competency required for all digital navigators includes developing a skillset needed to understand foundational smartphone knowledge and the ability to effectively teach others how to use a smartphone. Patients will vary in their smartphone literacy - some patients will have a strong understanding of their smartphone device but others will require more guidance. Additionally, patients may be able to use basic smartphone tools, but not know how to use these tools for health advantages. However, if patients understand foundational smartphone skills and how they can benefit their health, they can begin to build upon these skills independently. Therefore, it is imperative that the digital navigator understands these foundational skills so that they are able to instruct and guide patients and provide basic troubleshooting when necessary.

Since individuals will be entering the digital navigator training with various levels of skill sets around smartphone knowledge, a pre-training assessment will be given to all trainees to assess their ability to perform basic smartphone functions on both Apple and Android smartphones. Given that Apple and Android phones together compose over $98 \%$ of the smartphone market, we do not provide training for other models like Windows or BlackBerry phones. If the trainee demonstrates a sufficient knowledge of smartphone basics for Apple and Android phones, they will be able to skip Part 1 of this section of the training and begin with Part 2. The curriculum for both Part 1 and Part 2 of "Core Smartphone Skills" is presented in Table 2.

\section{Part 1: Navigating Smartphone Basics}

Part 1 of "Core Smartphone Skills" focuses on training for Objective 1: ensuring trainees have a basic understanding of how to use smartphone tools. The curriculum includes several tools related to core uses of smartphones that are important to be able assist patients with. As described previously, each of these tools will be broken down into tasks, each task into skills, and each skill into steps for the trainees to learn.

Using "internet/website" as an example, the tool (internet/website) is broken down into 3 skills (performing internet searches, navigating to a specific address, viewing history). The first skill, "performing internet searches," is broken down into 4 steps (see page 16 and 41 of the online suppl. Appendix). Trainers will teach trainees all steps for each task on both Apple and Android devices. In order to complete a task and continue with the training, the trainee will be required to perform one skill related to that task independently as chosen by the instructor. If the trainee is unable to complete the requested skill independently, they will be 


\section{Digital Biomarkers}

\begin{tabular}{l|l}
\hline DOI: 10.1159/000510144 & c 2020 The Author(s). Published by S. Karger AG, Basel
\end{tabular}

www.karger.com/dib

Wisniewski et al.: Digital Navigator Integration into Practice

Table 2. Core smartphone skills module

\section{Objectives}

At the completion of this module, trainees should:

1. Demonstrate a basic understanding of how to use smartphone tools (Part 1)

2. Independently utilize smartphone tools to benefit mental health (Part 2)

\begin{tabular}{|c|c|c|c|}
\hline $\begin{array}{l}\text { Tasks - demonstrate } \\
\text { effective use of: }\end{array}$ & Skills - Part 1 & Skills - Part 2 & Relevance \\
\hline Wifi and data & $\begin{array}{l}\text { Understanding difference } \\
\text { between wifi and data } \\
\text { Connect to wifi }\end{array}$ & None & $\begin{array}{l}\text { A wifi or data connection is often required to } \\
\text { perform many smartphone features }\end{array}$ \\
\hline Apps & Downloading an app & None & $\begin{array}{l}\text { The ability to download an app is necessary to } \\
\text { perform other smartphone skills }\end{array}$ \\
\hline Calls & $\begin{array}{l}\text { Making a call } \\
\text { Answering a call } \\
\text { Ignoring a call }\end{array}$ & $\begin{array}{l}\text { Relaxation by phone } \\
\text { Talking to loved ones }\end{array}$ & $\begin{array}{l}\text { Calling allows individuals to connect with others } \\
\text { and can be used for guided meditation }\end{array}$ \\
\hline Text messaging & $\begin{array}{l}\text { Creating a new message } \\
\text { Responding to a message } \\
\text { Sending pictures and videos } \\
\text { Sending messages to a group }\end{array}$ & Talking to support systems & $\begin{array}{l}\text { Text messaging allows individuals to connect with } \\
\text { others }\end{array}$ \\
\hline Internet & $\begin{array}{l}\text { Performing internet searches } \\
\text { Navigating to a specific address } \\
\text { Viewing history }\end{array}$ & $\begin{array}{l}\text { Watching videos } \\
\text { Finding mindfulness exercises } \\
\text { Researching accurate information }\end{array}$ & $\begin{array}{l}\text { Internet browsing allows individuals to look up } \\
\text { information and access self-guided exercises }\end{array}$ \\
\hline Listening to music & $\begin{array}{l}\text { Different music apps } \\
\text { Playing a specific song } \\
\text { Creating a playlist }\end{array}$ & $\begin{array}{l}\text { Finding podcasts } \\
\text { Creating a playlist }\end{array}$ & $\begin{array}{l}\text { Music is often used as a relaxation or grounding } \\
\text { mechanism }\end{array}$ \\
\hline Camera & $\begin{array}{l}\text { Taking a photo } \\
\text { Taking a video }\end{array}$ & $\begin{array}{l}\text { Photos and videos for mental } \\
\text { health }\end{array}$ & $\begin{array}{l}\text { Photos or videos that comfort an individual can be } \\
\text { used in times of stress }\end{array}$ \\
\hline Notes and reminders & $\begin{array}{l}\text { Creating a new note } \\
\text { Editing a note } \\
\text { Setting a reminder }\end{array}$ & Notes for mental health & $\begin{array}{l}\text { Setting reminders or writing notes can be a } \\
\text { grounding or relaxing exercise }\end{array}$ \\
\hline Clock & $\begin{array}{l}\text { Setting an alarm } \\
\text { Setting up "bedtime" } \\
\text { Using a timer }\end{array}$ & Creating a routine & Having a daily routine helps create healthy habits \\
\hline Calendar & $\begin{array}{l}\text { Creating an event } \\
\text { Creating an alert } \\
\text { Sending and accepting invitations }\end{array}$ & Setting a schedule & Setting a schedule can help reduce stress \\
\hline Health apps & $\begin{array}{l}\text { Viewing step count } \\
\text { Tracking walking or running } \\
\text { distance } \\
\text { Viewing sleep information }\end{array}$ & Exercise and mental health & Exercising regularly improves mood \\
\hline
\end{tabular}

Practice exercise

Trainers will have a prepared list of activities that each of the trainees will be required to perform. The list will include at least 1 skill from all tools for a total of

10 activities at a minimum. Trainers are able to assist trainees, if necessary, during the practice exercise. Example tasks for the practice exercise include:

- create a new note that states a certain sentence

- add an event to a calendar on a specific date

- connect to a particular wifi network

- check your step count on a particular day

\section{Assessment}

Testing of all "Core Smartphone Skills" material will be conducted via clinical scenarios. Each trainee will be presented with 3 sets of criteria. These criteria will be technology "prescriptions" for a patient. The digital navigator will have to make a recommendation for the patient based on the criteria provided. To ensure the digital navigator understands how to perform the functions, they will also be required to demonstrate their recommendation as if they were doing so with a patient. An in-depth criterion and scoring examples are provided below. Further case examples can be found in the online supplementary Appendix. Criteria:

Trainer: The clinician has stated the co-created goals for the patient include creating a routine for their day-to-day life and using technology to keep them accountable.

\begin{tabular}{|c|c|c|}
\hline \multicolumn{3}{|l|}{ Rubric } \\
\hline assessment & solution & communication \\
\hline Patient goal is creating routine & $\begin{array}{l}\text { Possible answers include: } \\
\text { Calendar: to set a schedule for each day } \\
\text { Timer: to keep track of timing tasks } \\
\text { Notes: to create a daily to-do list }\end{array}$ & $\begin{array}{l}\text { Able to demonstrate necessary skills: } \\
\text { Calendar: creating calendar events } \\
\text { Timer: setting a timer } \\
\text { Notes: creating a new note }\end{array}$ \\
\hline
\end{tabular}




\section{Digital Biomarkers}

Table 2 (continued)

\begin{tabular}{llll}
\hline Score metric & 1 & 2 & 3 \\
\hline Assessment & $\begin{array}{l}\text { Trainee was unable to identify any } \\
\text { patient goal }\end{array}$ & $\begin{array}{l}\text { Trainee was able to identify a patient goal, } \\
\text { but did not correctly identify routine }\end{array}$ & $\begin{array}{l}\text { Trainee was able to identify routine as the } \\
\text { patient goal }\end{array}$ \\
\hline Solution & $\begin{array}{l}\text { Trainee was unable to provide a } \\
\text { technology solution }\end{array}$ & $\begin{array}{l}\text { Trainee was able provide a solution, } \\
\text { but could not perform the task independently }\end{array}$ & $\begin{array}{l}\text { Trainee was able to provide a solution and } \\
\text { could independently perform the steps } \\
\text { required }\end{array}$ \\
\hline Communication & $\begin{array}{l}\text { Trainee was unable to demonstrate a } \\
\text { solution }\end{array}$ & $\begin{array}{l}\text { Trainee was able to demonstrate solution, } \\
\text { but did so in a disrespectful manner }\end{array}$ & $\begin{array}{l}\text { Trainee was able to demonstrate the solution } \\
\text { to patient and/or clinician in a respectable } \\
\text { manner }\end{array}$ \\
\hline
\end{tabular}

required to repeat all of the tasks within that module. For the evaluation of the internet/ website task, the trainee may then be asked to independently conduct an internet search (e.g., "search for digital mental health webpages" or "search for app evaluation webpages") to ensure they fully understood and retained the knowledge.

\section{Part 2: Smartphone Skills for Health}

Part 2 of "Core Smartphone Skills" training will focus on Objective 2: independently use smartphone tools to benefit mental health. The curriculum will further examine each of the previously learned tools and explain how these basic features can contribute to an individual's health. These techniques will largely be self-management of symptoms by the patient.

This is a sequential training paradigm - trainees are required to utilize the techniques covered in Part 1 to be successful in Part 2. Each tool will be the same, but the skills will now consist of ways this tool can be beneficial for an individual's health (e.g., tool: internet; skills: watching videos, finding mindfulness exercises, researching accurate information). As with Part 1, trainers will teach trainees these step by step instructions for each skill on both Apple and Android devices. Trainees will be required to demonstrate that they are able to perform each of these skills individually and have a sufficient understanding so they may demonstrate the skill to others. Since each tool will include a multitude of skills that could be used to benefit an individual's health management, training will focus on the most popular skills. After demonstration of each skill within a tool, trainees will be asked to brainstorm additional ways in which the task could be used for the benefit of the patient. This ensures the trainees have a sufficient understanding of the task and have the critical thinking skills to generate further ideas that may benefit a patient.

To practice these skills, trainers will provide a list of activities for trainees to complete. The activities will include at least one skill from all tools covered. Examples of skills to be performed for practice include, setting an alarm for a certain time, creating a calendar event for a particular day and time, or creating a bookmark for a specific webpage. Trainers will provide assistance to the trainees during practice if necessary.

Before advancing to the next module, all material within the "Core Smartphone Skills" module will be tested via a clinical scenario. Each trainee will be presented with 3 sets of criteria that provide details of patient goals that can be augmented with technology. The trainee will have to make a recommendation for the patients based on the criteria provided. To ensure the trainee understands how to perform the functions, they will also be required to demonstrate their recommendation via simulation/screenshare. A scoring rubric can be seen in Table 2 .

Of note, we do not offer details for wearables and sensors like blood glucose monitors or smartwatches because a specialized content with unique tools and skills will be necessary. The basic smartphone skills presented here will likely offer transferable knowledge that will aid the digital navigator in assisting with wearables and sensors. Our lack of detailed content offered for the myriad of these devices is not to diminish their clinical importance. We expect most sites will add new content around this as part of their curriculum and find related material helpful in understanding wearable devices [27]. 


\section{Digital Biomarkers}

\begin{tabular}{l|l}
\hline DOI: 10.1159/000510144 & $\begin{array}{l}\text { @ } 2020 \text { The Author(s). Published by S. Karger AG, Basel } \\
\text { www.karger.com/dib }\end{array}$ \\
\hline
\end{tabular}

Wisniewski et al.: Digital Navigator Integration into Practice

Table 3. Basic technology and troubleshooting module

\begin{tabular}{|c|c|c|}
\hline \multicolumn{3}{|c|}{$\begin{array}{l}\text { Objectives } \\
\text { At the completion of this module, trainees should: } \\
\text { 1. Have knowledge of common troubleshooting problems } \\
\text { 2. Demonstrate effective methods to solve basic troubleshooting issues }\end{array}$} \\
\hline $\begin{array}{l}\text { Tasks - demonstrate effective } \\
\text { management of: }\end{array}$ & Skills & Relevance \\
\hline Complications downloading an app & $\begin{array}{l}\text { Checking connections } \\
\text { Deleting apps }\end{array}$ & $\begin{array}{l}\text { The ability to download apps is essential for using technology for health. } \\
\text { Occasionally, apps may be slow to or unable to download }\end{array}$ \\
\hline Unknown account ID or password & Recovering passwords & $\begin{array}{l}\text { Accessing your account is required to download an app. An individual may not } \\
\text { remember their account username or password necessary to download an app }\end{array}$ \\
\hline Lack of storage space & $\begin{array}{l}\text { Deleting apps } \\
\text { Download size }\end{array}$ & $\begin{array}{l}\text { Storage space is necessary to download an app. Some patients may not have } \\
\text { available storage to download a new app }\end{array}$ \\
\hline App compatibility issues & Updating software & $\begin{array}{l}\text { The ability to download apps is essential for using technology for health. Some apps } \\
\text { may not be able to run on an individual's phone }\end{array}$ \\
\hline $\begin{array}{l}\text { Complications with wifi or data } \\
\text { connection }\end{array}$ & $\begin{array}{l}\text { Switching networks } \\
\text { Changing locations }\end{array}$ & $\begin{array}{l}\text { A wifi or data connection is necessary to download an app and often to use an app } \\
\text { after it has been downloaded. An inadequate connection can hinder this process }\end{array}$ \\
\hline Notification issues & Updating notification settings & $\begin{array}{l}\text { Notifications remind patients to use the app regularly. Although an app is set to } \\
\text { provide notifications, it is possible they may not appear }\end{array}$ \\
\hline App crashing & Closing and reopening apps & $\begin{array}{l}\text { The ability to download apps is essential for using technology for health. Apps may } \\
\text { be unable to load or quit unexpectedly }\end{array}$ \\
\hline $\begin{array}{l}\text { Bluetooth connections with } \\
\text { wearables }\end{array}$ & $\begin{array}{l}\text { Update apps } \\
\text { Disconnect and reconnect the } \\
\text { wearable } \\
\text { Reset the wearable }\end{array}$ & $\begin{array}{l}\text { Wearables can provide additional insight about fitness and environment data. } \\
\text { Some may have trouble connecting or disconnect spontaneously }\end{array}$ \\
\hline
\end{tabular}

Practice exercise

All "Basic Technology Troubleshooting" tools will be practiced via case scenarios and simulation. Trainers will have pre-prepared scenarios that they describe to each trainee. The trainees will then be asked to describe what potential solutions could be provided for each scenario. For practice, trainees will only be required to provide a verbal explanation.

\section{Assessment}

Testing will be performed via clinical scenarios. Each trainee will role-play with a trainer who will present the trainee with 3 technological issues to navigate. The digital navigator trainee should be able to walk through the steps required to solve these issues regardless of the device on which the issue is occurring (Android or iPhone). The trainee will be required to navigate to the corresponding pages to provide the solution. If the presented scenario is beyond the scope of the digital navigator's ability, the trainee should be prepared to provide information to the trainer on where they can go for further troubleshooting assistance. Scoring of the "Basic Technology Troubleshooting" module will be as follows. Further case examples can be found in the online supplementary Appendix. Scenario: "I normally use my smartwatch to track my step count, but it hasn't been working lately."

Rubric

assessment solution communication

Technology issue is wearable connection
Possible answers include: -Updating the wearable app -Issues with Bluetooth connection -Resetting the wearable
Able to demonstrate necessary skills:

-Navigate to app store to check for update

-Disconnecting and reconnecting the smartwatch to Bluetooth

-Following specific wearable instructions

\begin{tabular}{llll}
\hline Score metric & 1 & 2 & 3 \\
\hline Assessment & $\begin{array}{l}\text { Trainee was unable to identify the } \\
\text { technology issue }\end{array}$ & $\begin{array}{l}\text { Trainee was able to identify the technology } \\
\text { issue, but did not correctly identify the wearable } \\
\text { connection }\end{array}$ & $\begin{array}{l}\text { Trainee was able to identify the wearable } \\
\text { connection as the technology issue }\end{array}$ \\
\hline Solution & $\begin{array}{l}\text { Trainee was unable to provide a } \\
\text { technology solution }\end{array}$ & $\begin{array}{l}\text { Trainee was able to provide a solution but } \\
\text { could not perform the task independently }\end{array}$ & $\begin{array}{l}\text { Trainee was able to provide a solution and could } \\
\text { independently perform the steps required }\end{array}$ \\
\hline Communication & $\begin{array}{l}\text { Trainee was unable to demonstrate } \\
\text { a solution }\end{array}$ & $\begin{array}{l}\text { Trainee was able to demonstrate a solution, } \\
\text { but did so in a disrespectful manner }\end{array}$ & $\begin{array}{l}\text { Trainee was able to demonstrate a solution to the } \\
\text { patient and/or clinician in a respectable manner }\end{array}$
\end{tabular}




\section{Module 2: Basic Technology Troubleshooting}

Technological difficulties inevitably arise when using smartphones for clinical care. Therefore, a digital navigator should be prepared to handle basic technology troubleshooting. This module focuses on technological problems that are frequently seen and the most effective ways to handle each issue. Some of the most common technical issues include those presented in Table 3, and will serve as the tools for this module.

This list is not exhaustive, but includes the most common technology issues that may arise. On occasion, there may be more complex issues that are beyond the scope of the digital navigator's ability. For example, a patient who forgot their Apple ID password may not remember the answers to their security questions or are unable to access their email account to recover this password. In this case, the digital navigator should be able to direct the patient to resources that will be able to assist them. Given that different clinics will support different types of wearable devices and connected sensors, it is not possible to offer detailed skills for each. Local additions to the training will be necessary to ensure unique technology considerations are considered.

In this module, each tool is a common troubleshooting issue and each skill is a potential solution. Training will consist of in-depth descriptions of each technology issue with a list of potential troubleshooting solutions. Each skill will be demonstrated step by step so that the trainees have a sufficient understanding of each troubleshooting technique.

All tools will be practiced via simulation. Trainers will have prepared scenarios that they present to each trainee to assess knowledge and skills. The trainees will then be asked to describe what potential solutions could be provided for each scenario. For practice, trainees will only be required to provide a verbal explanation.

Testing will be performed via clinical scenarios. Each trainee will role-play with a trainer who will present the trainee with 3 technological issues to navigate. The trainee should be able to navigate to the corresponding webpages required to solve these issues regardless of which device the issue is occurring (Android or iPhone). A scoring rubric can be seen in Table 3.

\section{Module 3: App Evaluation}

The digital navigator will be required to recommend apps to both clinicians and patients. They should be able to quickly and efficiently evaluate new and updated apps to ensure they are both safe and potentially effective for the patient at hand to use. App evaluation training will be based on the American Psychiatric Association's (APA) App Evaluation Model [28], which also embodies the principles of personalizing app recommendations to each unique person and situation. Despite the name, this framework is broadly applicable to any healthcare field given its agnostic foundation specialty $[28,29]$ and has already been utilized by diverse groups, such as NYC Well [30]. A 2020 review of frameworks for evaluating apps noted the APA framework offered the most considerations for security and privacy compared to others reviewed [31]. That said, the goal of this module is to teach universal evaluation skills and many other frameworks could be substituted as necessary.

The model includes a 5-step process focusing on background information, privacy and security, evidence, ease of use, and interoperability. Most apps will not meet the criteria of all 5 categories. For example, an app that is easy to use and visually appealing may not have scientific evidence to evaluate its effectiveness, or an app with secure privacy measures may be difficult for a client to use. Therefore, the digital navigator should be prepared to discuss these steps with a client and clinician and help each decide which criteria are most important for the app to meet. At the completion of training, the digital navigator should be able to assess the needs for an app

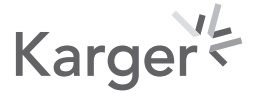




\section{Digital Biomarkers}

\begin{tabular}{l|l}
\hline DOI: $10.1159 / 000510144$ & $\begin{array}{l}\text { (c) } 2020 \text { The Author(s). Published by S. Karger AG, Basel } \\
\text { www.karger.com/dib }\end{array}$
\end{tabular}

Wisniewski et al.: Digital Navigator Integration into Practice

Table 4. App evaluation module

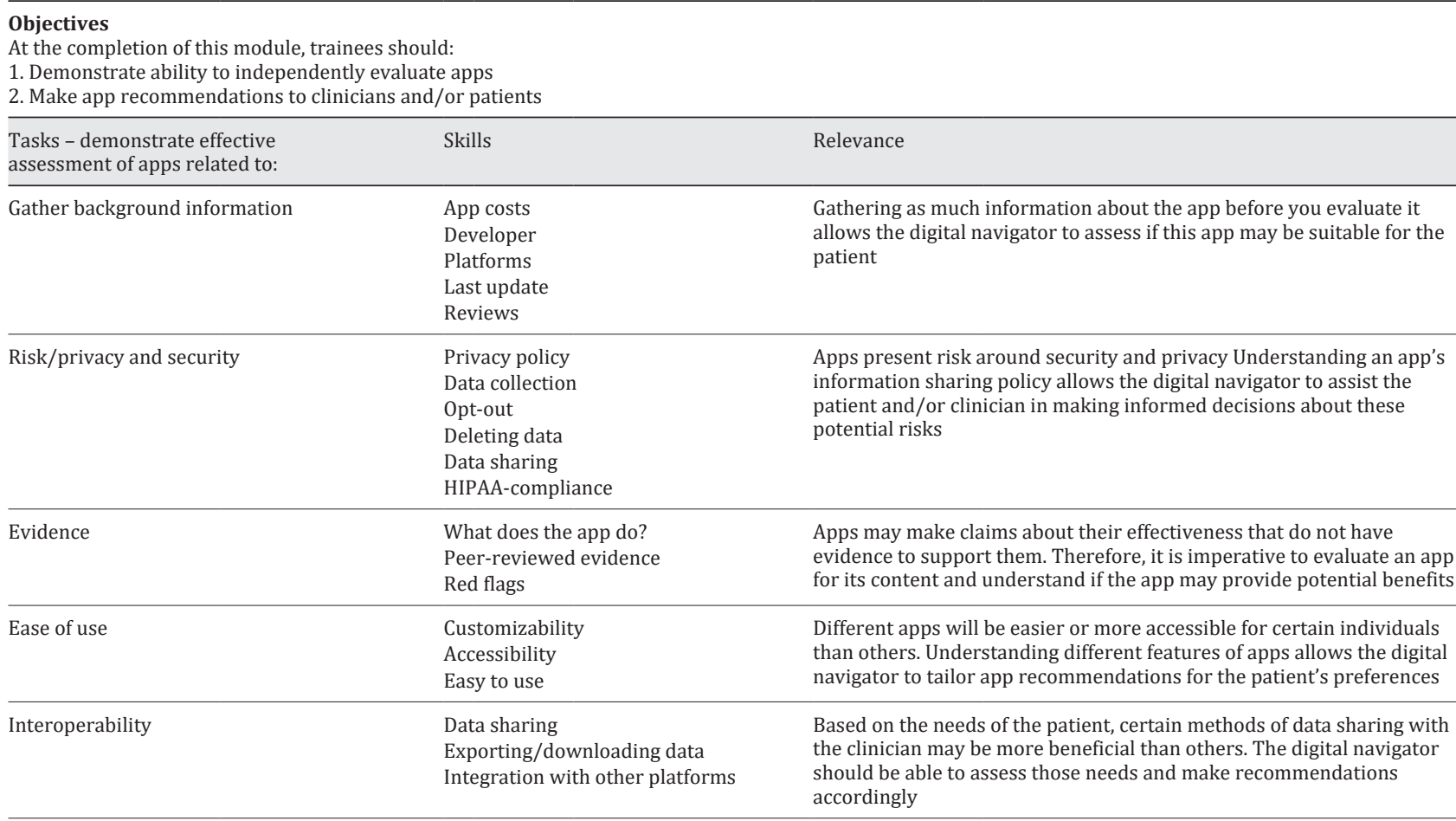

\section{Practice exercise}

Trainees will practice app evaluation by evaluating 5 apps. Their interrater reliability will be assessed. The 5 apps will vary in their quality and content to assure the trainees can sufficiently rate a variety of apps. Apps used for evaluation will be continually updated to ensure consistency in difficulty of rating required by trainees to pass their training. A scoring example is as follows:

App 1. Low-quality app. This should have no privacy policy, questionable developer, updated over 180 days ago.

Trainees should NOT RECOMMEND this app.

App 2. Policy privacy present, but not detailed or does not provide adequate information. App should contain a "red flag."

Trainees should NOT RECOMMEND this app.

App 3. App should have a privacy policy present with sufficient information provided. App should contain no "red flags." Usability features should be average or basic. Trainees may recommend this app or not, based on patient needs, as it meets basic safety and evidence requirements but its interface is mediocre. Therefore, some patients may find it useful while others may not

App 4 and 5. Strong privacy policy, updated regularly, relatively easy to use. App 4 and 5 should differ based on their usability and interoperability.

Trainees should RECOMMEND these apps and be able to distinguish when they would recommend these apps to patients based on their ease of use and integration capabilities.

\section{Assessment}

Trainers will provide trainees with 5 case scenarios. These scenarios will outline details of app criteria for a clinician or a patient. Trainees will be required to make an app recommendation based on the provided criteria. A scoring example is as follows. Further examples can be found in the online supplementary Appendix.

Case scenario: The patient is looking for an app so that they can journal their thoughts in times of stress. They would like to be able to send their journal entries to their clinician periodically. They are highly concerned with privacy and would like the option to delete their data after a few weeks of using the app.

Rubric

assessment

solution

Trainee should be able to assess the criteria to

determine what app qualities to look for.

- Journaling feature

- Data sharing

- Privacy policy and data deletion

Trainee should be able to make an app recommendation based on these criteria communication

The trainee should be able to provide reasoning as to why they chose the given app and demonstrate how to use it to the trainer. We understand that it may not always be possible to find an app based on all criteria listed. Therefore, the trainee should be able to provide reasoning behind their recommendation and whether or not the app meets all of the provided criteria

\begin{tabular}{|c|c|c|c|}
\hline Score metric & 1 & 2 & 3 \\
\hline Assessment & $\begin{array}{l}\text { Trainee was unable to identify the } \\
\text { main app criteria provided in the case } \\
\text { scenario }\end{array}$ & $\begin{array}{l}\text { Trainee was able to identify some of the criteria } \\
\text { provided in the scenario, but not all }\end{array}$ & $\begin{array}{l}\text { Trainee was able to assess all app criteria } \\
\text { provided in the case scenario }\end{array}$ \\
\hline Solution & $\begin{array}{l}\text { Trainee was unable to recommend an } \\
\text { app based on the given criteria }\end{array}$ & $\begin{array}{l}\text { Trainee was able to recommend an app, but the } \\
\text { app did not meet all of the criteria provided in the } \\
\text { case scenario }\end{array}$ & $\begin{array}{l}\text { Trainee was able to make a sufficient app } \\
\text { recommendation based on the app } \\
\text { criteria }\end{array}$ \\
\hline Communication & $\begin{array}{l}\text { Trainee was unable to provide } \\
\text { reasoning to the trainer as to why } \\
\text { they recommended a particular app }\end{array}$ & $\begin{array}{l}\text { Trainee was able to provide some reasoning to the } \\
\text { trainer as to why they recommended a particular app, } \\
\text { but not in all areas of the specified criteria }\end{array}$ & $\begin{array}{l}\text { Trainee was able to sufficiently explain } \\
\text { their app recommendation to trainers }\end{array}$ \\
\hline
\end{tabular}


as described by the clinician and/or the client, identify and evaluate an app that would effectively meet those needs, and instruct the clinician and client on how to use the app.

App evaluation training will be conducted in the following format:

Each category from the APA app evaluation framework will be listed as the tool, and the evaluation steps within that category will be listed as a skill. Trainees will be taught the framework in this format. For example, one of the listed tools - privacy and security - contains privacy policies as a skill. Many apps do not have a privacy policy, and even the ones that do may not be adequate. Therefore, in this skill the trainer will teach trainees how to locate the privacy policy of an app if there is one listed.

After reviewing the APA App Evaluation Framework in full, trainees will be instructed on the Division of Digital Psychiatry App Evaluation Database. This database is an expansion upon the APA App Evaluation framework and allows individuals to rate apps based on 105 objective rating questions. The principal taught in this app evaluation can also be applied to non-medical apps for conditions that patients may suffer from, including hypertension, diabetes, and cardiovascular diseases, among others. Trainees will apply their new knowledge of the app evaluation framework to app ratings on the App Evaluation Database. As a practice exercise, trainees will rate 2 apps on the app evaluation database. The apps used for evaluation on the database can be chosen arbitrarily, although all trainees should rate the same apps. A trainees' interrater reliability will be assessed both between current ratings available on the database as well as ratings with other trainees to ensure high concordance.

To assess trainees' understanding of app evaluation, trainers will administer 5 sets of criteria for an app and the trainees will be asked to make app recommendations based on the provided criteria. A scoring rubric can be found in Table 4 .

\section{Module 4: Clinical Terminology and Data}

\section{Part 1: Clinical Terminology}

The digital navigator position is not a clinical role. However, it is imperative the digital navigator have a foundational clinical understanding of health terminology, symptomology, and practices so the navigator can have a discussion with the clinician and client around data outputs. The terminology and policies that are necessary for the digital navigator to be familiar with will vary depending on the clinical specialty (e.g., internal medicine, psychiatry, pediatrics), practice setting (e.g., inpatient vs. outpatient), and population in which the digital navigator will work.

Trainers will need to select terminology and policies that are relevant for the trainees. The list below includes potential clinical terms used in an outpatient adult psychiatry clinic: Therapeutic Alliance; Rapport; Cultural Competency; Confidentiality; Health Insurance Portability and Accountability Act (HIPAA); Professional Boundaries. This is not an exhaustive list but rather identifies examples of how clinical terminology can be selected. After choosing key phrases, the next step will be selecting a standardized definition for all of the terms listed. Selecting definitions that are mutually agreed upon by various level stakeholders will be key to implementing and creating shared language.

Finally, ensuring the digital navigator understands the mission of the clinical work being done (e.g., employment based, recovery oriented) and providing an example of treatment goals will help the them gain a deeper understanding of the types of technological resources they may provide to patients and clinicians.

\section{Part 2: Clinical Data and Privacy}

One of the main responsibilities of the digital navigator is to translate and summarize app data for clinicians and maintain patient privacy. As seen previously, different data streams 


\section{Digital Biomarkers}

\begin{tabular}{l|l}
\hline DOI: 10.1159/000510144 & $\begin{array}{l}\text { @ } 2020 \text { The Author(s). Published by S. Karger AG, Basel } \\
\text { www.karger.com/dib }\end{array}$
\end{tabular}

Wisniewski et al.: Digital Navigator Integration into Practice

Table 5. Clinical terminology and data module

\begin{tabular}{|c|c|c|}
\hline \multicolumn{3}{|c|}{$\begin{array}{l}\text { Objectives } \\
\text { At the completion of this module, trainees should: } \\
\text { 1. Obtain a basic understanding of clinical terminology } \\
\text { 2. Demonstrate the ability to summarize potentially clinically relevant information from graphs and app data }\end{array}$} \\
\hline $\begin{array}{l}\text { Tasks - demonstrate effective } \\
\text { knowledge of: }\end{array}$ & Skills & Relevance \\
\hline Diagnoses & $\begin{array}{l}\text { Depressive disorders } \\
\text { Anxiety disorders }\end{array}$ & $\begin{array}{l}\text { Understanding the foundational language of clinical practice, the mission of } \\
\text { clinical work, and examples of treatment goals will aid a navigator in } \\
\text { successfully carrying out their duties }\end{array}$ \\
\hline Clinical "red flags" & $\begin{array}{l}\text { Warning signs } \\
\text { When to seek help }\end{array}$ & $\begin{array}{l}\text { Because the digital navigator is not a clinical role, they should be prepared to } \\
\text { seek clinical help when necessary }\end{array}$ \\
\hline $\begin{array}{l}\text { HIPAA compliance and } \\
\text { confidentiality }\end{array}$ & $\begin{array}{l}\text { Adhere to HIPAA regulations } \\
\text { Understand and practice program-specific } \\
\text { compliancy and confidentiality protocols }\end{array}$ & $\begin{array}{l}\text { Since Digital Navigators will be working in clinical settings, understanding } \\
\text { federal HIPPA regulations and the program's compliancy and confidentiality } \\
\text { protocols will help to ensure patient protection at all levels }\end{array}$ \\
\hline Data streams & $\begin{array}{l}\text { Active data } \\
\text { Passive data }\end{array}$ & $\begin{array}{l}\text { The digital navigator will require a thorough understanding of the many } \\
\text { types of data collected via apps and other technology so they are prepared to } \\
\text { make recommendations based on treatment goals }\end{array}$ \\
\hline
\end{tabular}

Practice exercise

A practice worksheet should be created based upon clinic needs that tests the trainees on the reviewed definitions. This worksheet can be formatted as the trainers see fit. Please see the online supplementary Appendix for an example.

\section{Assessment}

Trainees will be assessed on "Clinical Data Interpretation and Safety" by evaluating 5 sets of app data presented in varying modalities. Trainees will be required both to summarize the relevance of the presented data as well as alert the clinician of possible warning signs. An example is provided below.

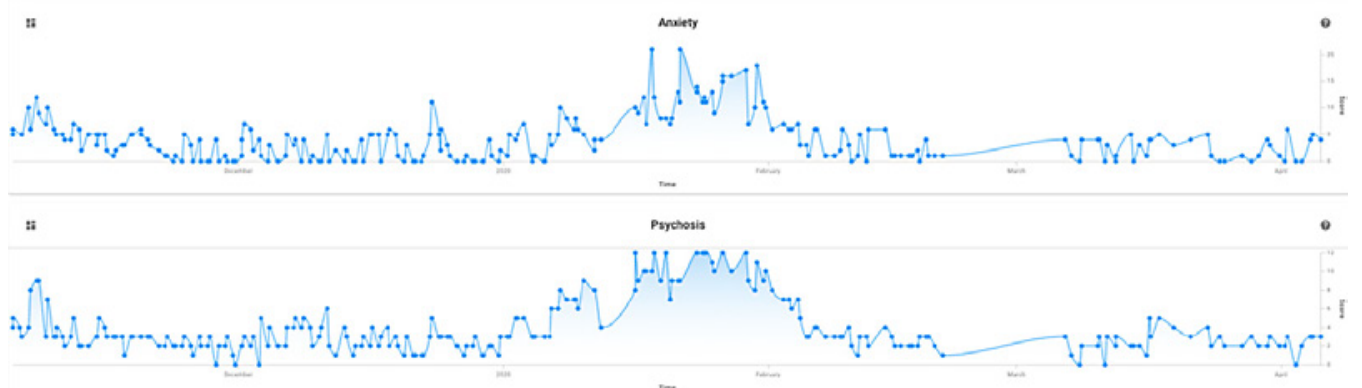

Rubric

assessment

The figure (above) displays an individual's anxiety and psychosis scores over time

\section{solution}

Elevated levels of both anxiety and psychosis are apparent between January and February 2020. communication

Trainee is able to effectively describe relevant information from the graph to a clinician

\begin{tabular}{|c|c|c|c|}
\hline Score metric & 1 & 2 & 3 \\
\hline Assessment & $\begin{array}{l}\text { Trainee was unable to determine the } \\
\text { relevance of the graph }\end{array}$ & $\begin{array}{l}\text { Trainee understands parts of the figure, but not all (i.e., } \\
\text { understands that the graph shows anxiety/psychosis } \\
\text { scores, but not over time; cannot discern if high or low } \\
\text { scores are clinically relevant) }\end{array}$ & $\begin{array}{l}\text { The trainee is able to understand the } \\
\text { graph }\end{array}$ \\
\hline Solution & $\begin{array}{l}\text { Trainee was unable to discern } \\
\text { information of potential clinical } \\
\text { relevance from the graph }\end{array}$ & $\begin{array}{l}\text { Trainee was able to discern some clinical relevance, but } \\
\text { could not identify all aspects or incorrectly interpreted } \\
\text { key points }\end{array}$ & $\begin{array}{l}\text { Trainee was able to interpret all } \\
\text { aspects of the graph that may provide } \\
\text { clinical relevance }\end{array}$ \\
\hline Communication & $\begin{array}{l}\text { Trainee was unable to communicate } \\
\text { the relevance of the graph in an } \\
\text { understandable, appropriate manner }\end{array}$ & $\begin{array}{l}\text { Trainee was able to communicate the relevance of the } \\
\text { graph, but did so in a disrespectful manner }\end{array}$ & $\begin{array}{l}\text { Trainee was able to demonstrate skills } \\
\text { to the patient and/or clinician in a } \\
\text { respectable manner }\end{array}$ \\
\hline
\end{tabular}

(e.g., surveys, step count, sleep data) collected from a smartphone can provide a variety of clinical insights [32]. Therefore, the digital navigator should be prepared to interpret multiple types of information. In working with any health-related data, it is critical that the digital navigator understands the ethical, professional, and legal obligations to protect and secure clini- 
cally related data. While we do not propose a specific training for privacy as we assume most clinics and hospitals will already support that function with exiting programing, we do not mean to minimize its importance.

In Part 2 of this module, trainees will be required to interpret data from various data streams to ensure they are able to understand the valuable information each provides. This module will focus on expanding upon what types of information can come from apps classified as active data (collected from an individual while they are using the app) or passive data (collected in the background regardless of whether or not the patient is using the app).

By completion of the module, trainees should be able to understand how each data stream can be used for clinical information and be able to recommend a particular data stream to a clinician and/or patient based on their technology needs. For example, if the data stream in question is survey responses, the trainees will be required to understand that this is an active data stream and can provide information about symptomology over time or symptom correlation. If a patient were to say they are interested in understanding how their anxiety fluctuates throughout the week, the trainee, in consultation with the treating clinician, should be able to recommend a survey tool to them.

Trainees will be presented with an example of varying graphs and asked to interpret the relevance of each one. Once the trainee has completed their interpretations, the trainees and the training instructors will discuss the graphs to ensure all trainees have an understanding of the main results.

Upon completion of discussion of all presented graphs, trainees will be assessed on new graphs to evaluate their ability to relay relevant data individually. Each trainee will be asked to evaluate 5 datasets. Trainees will be required to summarize the relevance of graphical depictions of data such as the graph shown in Table 5. A scoring rubric is also presented in Table 5.

\section{Module 5: Engagement Techniques}

In order for the patient-provided data to have potential clinical relevance, the patient must use the app enough to yield a sufficient level of information. Therefore, the digital navigator must be able to efficiently engage the patient in order to help maintain motivation of app use and understand any technology barriers that may arise.

Module 5 will focus on engagement techniques, specifically interviewing skills. The engagement skills for this section will be pulled from motivational interviewing techniques, specially part of the OARS methods (open-ended questions, affirmation, reflective listening, and summaries) [33].

The digital navigator should be able to address technological issues or changes in engagement. Therefore, it will be important for the digital navigator to learn the skill of asking clarifying, open-ended questions with patients and clinicians. When used with patients, clarifying and open-ended questions may lead a digital navigator to a deeper understanding of how a patient would like to use technology, as well as identify strengths the patient possess and barriers which may negatively impact app engagement.

As previously mentioned, the unique position of the digital navigator allows the person to be part of the care team, but the position remains a non-clinical role. Therefore, appropriate professional boundaries will be critical for the person to uphold and understand. However, since the digital navigator is part of the care team, their role may not always be as clear to patients or outside providers. For these reasons, the digital navigator should not answer questions out of their skill set and should refer them to appropriate channels in a timely manner. Examples of how a digital navigator can handle such situations will be provided in the case scenarios. 
Table 6. Engagement techniques module

\begin{tabular}{|c|c|c|}
\hline \multicolumn{3}{|c|}{$\begin{array}{l}\text { Objectives } \\
\text { At the completion of this module, trainees should: } \\
\text { 1. Learn to verbally engage with patients in order to maintain app utilization } \\
\text { 2. Communicate questions and concerns to appropriate channels as needed } \\
\text { 3. Assist with the maintenance of trust and transparency in order to aid the therapeutic process }\end{array}$} \\
\hline Tasks - demonstrate effective use of: & Skills & Relevance \\
\hline Interviewing methods & $\begin{array}{l}\text { Asking for clarification } \\
\text { Open-ended questions }\end{array}$ & $\begin{array}{l}\text { By being the point person for data information and having face to face } \\
\text { conversations with patients, the digital navigator can assist the clinician and } \\
\text { patient in clarifying any data or app confusion }\end{array}$ \\
\hline Communication methods & Refer patient to appropriate sources & $\begin{array}{l}\text { When a patient asks a digital navigator a question or conveys a concern which } \\
\text { the digital navigator cannot address, it is important the navigator refers the } \\
\text { patient to an appropriate party so the issue can be rectified }\end{array}$ \\
\hline Convening trust and transparency & $\begin{array}{l}\text { Acknowledge role limitations which } \\
\text { conveys honesty and trust }\end{array}$ & $\begin{array}{l}\text { Trust and transparency are crucial to the therapeutic alliance, but the digital } \\
\text { navigator is not directly part of the dyad. However, the navigator remains } \\
\text { part of the care team and, therefore, acts as a representative of trust and } \\
\text { transparency throughout the digital navigator meetings }\end{array}$ \\
\hline
\end{tabular}

\section{Practice exercise}

Case scenario as seen in the online supplementary Appendix.

\section{Assessment}

The assessment will utilize a case scenario and ask participants to select the best engagement technique for the scenario. See the online supplementary Appendix for more examples.

\begin{tabular}{|c|c|c|c|}
\hline \multicolumn{4}{|l|}{ Rubric } \\
\hline \multicolumn{2}{|l|}{ assessment } & solution & communication \\
\hline \multicolumn{2}{|c|}{ Case scenario utilizing various engagement techniques } & $\begin{array}{l}\text { Participants will choose the best possible } \\
\text { answer from the list provided }\end{array}$ & $\begin{array}{l}\text { Trainee will choose the best engagement } \\
\text { technique for the situation and briefly } \\
\text { explain their reasoning }\end{array}$ \\
\hline Score metric & 1 & 2 & 3 \\
\hline Assessment & $\begin{array}{l}\text { Trainee was unable to identify that an } \\
\text { engagement technique was needed }\end{array}$ & $\begin{array}{l}\text { Trainee was able to identify when an } \\
\text { engagement technique was needed between } \\
60 \text { and } 79 \% \text { of the time }\end{array}$ & $\begin{array}{l}\text { Trainee was able to identify when an } \\
\text { engagement technique was needed } 80 \% \\
\text { or more of the time }\end{array}$ \\
\hline Solution & $\begin{array}{l}\text { Trainee was unable to select an appropriate } \\
\text { engagement technique }\end{array}$ & $\begin{array}{l}\text { Trainee was able to select an appropriate } \\
\text { engagement technique between } 60 \text { and } 79 \% \\
\text { of the time }\end{array}$ & $\begin{array}{l}\text { Trainee was able to select appropriate } \\
\text { engagement techniques } 80 \% \text { or more of } \\
\text { the time }\end{array}$ \\
\hline Communication & $\begin{array}{l}\text { Trainee was unable to communicate the } \\
\text { reasoning behind the engagement technique }\end{array}$ & $\begin{array}{l}\text { Trainee was able to communicate the } \\
\text { reasoning behind the selected engagement } \\
\text { technique between } 60 \text { and } 79 \% \text { of the time }\end{array}$ & $\begin{array}{l}\text { Trainee was able to communicate the } \\
\text { reasoning behind the selected } \\
\text { engagement technique } 80 \% \text { or more of } \\
\text { the time }\end{array}$ \\
\hline
\end{tabular}

Trust and transparency will be reviewed through engagement techniques, specifically summarization and questions. Utilizing part of Bordin's definition of the therapeutic alliance - collaboration - the cornerstone of the digital navigator's definition of trust will be a shared understanding of the patient's goals [34]. The most direct way a digital navigator can understand the patient's goals and most effective ways a patient will use an app is through summarizing and reflective listening ( 2 more motivational interviewing techniques). Again, to make these engagement techniques more concrete, case scenarios will be utilized to show examples of these techniques in real-world scenarios. A scoring rubric is provided in Table 6 .

\section{Discussion}

As interest in digital health expands, so does the need for a new role to guide technology use and implementation. Studies typically describe methods, interventions, technologies used, and care outcomes rather than what clinical skills are needed and how they are developed or acquired. Education/training appears either narrowly limited to use of a specific 
technology for an intervention, or about the importance of patient buy-in, usability, and engagement. This manuscript presents a training aimed to provide practical instruction on using technology to improve access to and the quality of healthcare. Those completing the training, whether as a first role in healthcare or as a seasoned clinician, will likely emerge better able to integrate and support the use of technology in care. The combination of didactic learning, hands-on experience, simulation, and case presentations offer a multimodal learning experience designed to provide versatile and practical knowledge. While the focus of each training will vary based on the unique clinical needs and settings of a site, the core lessons offered here are more invariant and should prove of benefit in diverse settings.

The implementation of the digital navigator position into health clinics will require more than just training, including some degree of workflow restructuring and funding. Academic health centers and health systems may assume that clinicians and systems are adapting to technology - and they are using video in the COVID-19 era - but clinical, technological, and administrative workflow is still in progress and many clinicians struggle to use new technologies or believe that they do not have time to do "the little things" that make it work [15]. Even more surprisingly, they may see apps, sensors, wearables, and social media, as "outside" of regular care. The flexibility of the digital navigator position allows a diverse workforce to assume the role and helps to minimize clinic disruption. Just as radiology technicians began as assistants who were already employed at the clinic [35], we propose this position could initially be filled by existing members of the healthcare team, peers with lived experience, a digital native's first job in healthcare, or as an expansion of the duties of a clinician.

Finally, because technology is continually and rapidly evolving, so will the role of the digital navigator. Undergraduate medical education and graduate medical education councils and professional organizations are providing guidance on the use of technology, but have not yet put forward competencies to ensure quality care [36,37]. This skill/competency framework will facilitate implementation, training, and evaluation. As technological innovation is moving so quickly, annual recertification will need to be conducted for quality control of skills and adjustment to relevant technological advances for the curricula. The recertification process could also explore the digital navigator role in general, and in relation to service delivery (e.g., interprofessional teams, stepped and/or integrated care models). As it becomes clear who the digital navigator serves and types of technology used, subtypes of digital navigators may bare consideration with additional/adjusted training requirements. Recertification processes are typically short and consist of 1-2 modules that are administered online. Offering the training without certification may be necessary at first, as a sustainable system of certification must first be in place. While we do not discuss how such a system could be sustainable here, if the training improves uptake and adherence to digital health technologies, resulting cost savings in care could make offering digital navigator training appealing.

There are limitations to our proposed training. Currently, this curriculum is based on our team's experience with the digital navigator role and has not yet been implemented in other settings outside our team. As noted throughout the paper, customization may be necessary for unique use cases and technology focuses beyond those common topics discussed here. Issues of interrater reliability for evaluation metrics must still be established. Therefore, this training serves as an initial foundation and will require amendments as necessary once training begins. Furthermore, the training above has been written for in-person administration. This allows for adjustments to be easily made as the training evolves and allows for more efficient teaching techniques. However, the goal is to eventually administer this training online. This would not only allow for a larger audience, so that more individuals can complete digital navigator training, but it would also allow for more individuals to conduct the training eventually as well. As a first step, there is a need to train a series of trainers so that this can be offered broadly, and an online webinar series may be a viable option in light of COVID-19.

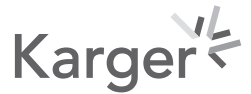


As the need for technology integration into healthcare continues to grow around the world [39], so does the need for a new role on the care team to help implement these changes. The training outlined here provides practical and actionable steps that can be taken to move this role from theory into practice. This paper also outlines a practical way in which training can be implemented while leaving room for flexibility and customization to allow for the consideration of new technologies, new global health uses, and new clinical demands.

\section{Acknowledgements}

We would like to thank the UC Davis School of Medicine and Department of Psychiatry and Behavioral Sciences, and the Veteran Affairs Northern California Health Care System and Mental Health Service.

\section{Statement of Ethics}

This study was exempt from Institutional Review Board review.

\section{Conflict of Interest Statement}

None of the authors have any financial or other disclosures. J.T. reports unrelated research support form Otsuka.

\section{Funding Sources}

There are no funding sources to declare.

\section{Author Contributions}

J.T. and H.W.: conception and design. J.T.: administrative support. All authors: collection and assembly of data, data analysis and interpretation, manuscript writing, and final approval of the manuscript.

\section{References}

1 Dorsey ER, Topol EJ. State of Telehealth. N Engl J Med. 2016 Jul;375(2):154-61.

2 Wisniewski H, Torous J. Digital navigators to implement smartphone and digital tools in care. Acta Psychiatr Scand. 2020 Apr;141(4):350-5.

3 Torous J, Jän Myrick K, Rauseo-Ricupero N, Firth J. Digital Mental Health and COVID-19: Using Technology Today to Accelerate the Curve on Access and Quality Tomorrow. JMIR Ment Health. 2020;7(3):e18848.

4 Greenhalgh T, Wherton J, Papoutsi C, Lynch J, Hughes G, Hinder S, et al. Beyond adoption: a new framework for theorizing and evaluating nonadoption, abandonment, and challenges to the scale-up, spread, and sustainability of health and care technologies. J Med Internet Res. 2017 Nov 1;19(11):e367.

5 Kim JH, Desai E, Cole MB. How The Rapid Shift To Telehealth Leaves Many Community Health Centers Behind During The COVID-19 Pandemic. Health Affairs. 2020;26(4).

6 Jacob C, Sanchez-Vazquez A, Ivory C. Social, Organizational, and Technological Factors Impacting Clinicians' Adoption of Mobile Health Tools: Systematic LiteratureReview. JMIR Mhealth Uhealth. 2020;8(2):e15935.

7 Lattie EG, Nicholas J, Knapp AA, Skerl JJ, Kaiser SM, Mohr DC. Opportunities for and Tensions Surrounding the Use of Technology-Enabled Mental Health Services in Community Mental Health Care. Adm Policy Ment Health. 2020 Jan;47(1):138-49. 
Wisniewski et al.: Digital Navigator Integration into Practice

8 Hilty DM, Torous J, Parish M, et al. A Literature Review Comparing Clinicians' Approaches and Skills to In-Person, Synchronous, and Asynchronous Care: Moving Toward Competencies to Ensure Quality Care. Telemed J E Health. 2020, Online ahead of print.

9 Cowan KE, McKean AJ, Gentry MT, Hilty DM. Barriers to Use of Telepsychiatry: Clinicians as Gatekeepers. Mayo Clin Proc. 2019 Dec;94(12):2510-23.

10 Mahmood S, Hasan K, Colder Carras M, Labrique A. Global Preparedness Against COVID-19: We Must Leverage the Power of Digital Health. JMIR Public Health Surveill. 2020 Apr;6(2):e18980.

11 Labrique AB, Wadhwani C, Williams KA, Lamptey P, Hesp C, Luk R, et al. Best practices in scaling digital health in low and middle income countries. Global Health. 2018 Nov;14(1):103.

12 Hilty DM, Crawford A, Teshima J, Chan S, Sunderji N, Yellowlees PM, et al. A framework for telepsychiatric training and e-health: competency-based education, evaluation and implications. Int Rev Psychiatry. 2015; 27(6):569-92.

13 Zalpuri I, Liu H, Stubbe D, Wrzosek M, Sadhu J, Hilty D. A competency-based framework for social media for trainees, faculty and others. Acad Psychiatry. 2018;42(6):808-17.

14 Hilty D, Chan S, Torous J, Luo J, Boland R. A framework for competencies for the use of mobile technologies in psychiatry and medicine: scoping review. JMIR Mhealth Uhealth. 2020 Feb;8(2):e12229.

15 Hilty DM, Unützer J, Ko DG, Luo J, Worley LL, Yager J. Approaches for departments, schools and health systems to better implement technologies used for clinical care and education. Acad Psychiatry. 2019 Dec;43(6):611-6.

16 Gunnell D, Appleby L, Arensman E, Hawton K, John A, Kapur N, et al.; COVID-19 Suicide Prevention Research Collaboration. Suicide risk and prevention during the COVID-19 pandemic. Lancet Psychiatry. 2020 Jun;7(6):468-71.

17 Huang Z, Semwal M, Lee SY, Tee M, Ong W, Tan WS, et al. Digital health professions education on diabetes management: systematic review by the Digital Health Education Collaboration. J Med Internet Res. 2019 Feb; 21(2):e12997.

18 Turakhia MP, Desai SA, Harrington RA. The outlook of digital health for cardiovascular medicine: challenges but also extraordinary opportunities. JAMA Cardiol. 2016 0ct;1(7):743-4.

19 van de Graaf DL, Schoonman GG, Habibović M, Pauws SC. Towards eHealth to support the health journey of headache patients: a scoping review. J Neurol. 2020, Online ahead of print.

20 Raney L, Bergman D, Torous J, Hasselberg M. Digitally driven integrated primary care and behavioral health: how technology can expand access to effective treatment. Curr Psychiatry Rep. 2017 Sep;19(11):86.

21 Wisniewski H, Torous J. Digital navigators to implement smartphone and digital tools in care. Acta Psychiatr Scand. 2020 Apr;141(4):350-5.

22 Brasier N, Eckstein J. Sweat as a Source of Next-Generation Digital Biomarkers. Digit Biomark. 2019 Dec;3(3): 155-65.

23 Dorsey ER, Glidden AM, Holloway MR, Birbeck GL, Schwamm LH. Teleneurology and mobile technologies: the future of neurological care. Nat Rev Neurol. 2018 May;14(5):285-97.

24 Ramirez E, Marinsek N, Bradshaw B, Kanard R, Foschini L. Continuous Digital Assessment for Weight Loss Surgery Patients. Digit Biomark. 2020 Mar;4(1):13-20.

25 Flaten HK, St Claire C, Schlager E, Dunnick CA, Dellavalle RP. Growth of mobile applications in dermatology 2017 update. Dermatol Online J. 2018 Feb;24(2):13030/qt3hs7n9z6.

26 Kirkpatrick J, Kirkpatrick W. The Kirkpatrick four levels: a fresh look after 50 years, 1959-2009. 2009. http:// www.managesmarter.com/managesmarter/images/pdfs/trg_20090417_kirkpatrickwhitepaper.pdf.

27 Coravos A, Doerr M, Goldsack J, Manta C, Shervey M, Woods B, et al. Modernizing and designing evaluation frameworks for connected sensor technologies in medicine. NPJ Digit Med. 2020 Mar;3:37.

28 Torous JB, Chan SR, Gipson SY, Kim JW, Nguyen TQ, Luo J, et al. A hierarchical framework for evaluation and informed decision making regarding smartphone apps for clinical care. Psychiatr Serv. 2018 May;69(5):498-500.

29 Henson P, David G, Albright K, Torous J. Deriving a practical framework for the evaluation of health apps. Lancet Digit Health. 2019 Jun;1(2):e52-4.

30 NYC Well. App library. https://nycwell.cityofnewyork.us/en/app-library/.

31 Nurgalieva L, O'Callaghan D, Doherty G. Security and Privacy of mHealth Applications: A Scoping Review. IEEE Access. 2020 Jun; 8:104247-68.

32 Wisniewski H, Henson P, Torous J. Using a Smartphone App to Identify Clinically Relevant Behavior Trends via Symptom Report, Cognition Scores, and Exercise Levels: A Case Series. Front Psychiatry. 2019 Sep;10:652.

33 Rosengren DB. Building motivational interviewing skills: a practitioner workbook. New York: Guilford Press; 2009.

34 Bordin ES. Theory and research on the therapeutic working alliance: new directions. In: Hovarth AO, Greenberg LS, editors. The working alliance: theory, research, and practice. Hoboken, Wiley; 1994. pp. 13-37.

35 American Society of Radiologic Technologists. History of the American Society of Radiologic Technologists. https://www.asrt.org/main/about-asrt/asrt-history (accessed May 1, 2020).

36 Hilty DM, Maheu MM, Drude KP, Hertlein KM. The need to implement and evaluate telehealth competency frameworks to ensure quality care across behavioral health professions. Acad Psychiatry. 2018 Dec;42(6): 818-24.

37 Maheu MM, Drude KP, Hertlein KM, Hilty DM. A framework for interprofessional telebehavioral health competencies: implementation and challenges moving forward. Acad Psychiatry. 2018 Dec;42(6):825-33.

38 Babrak LM, Menetski J, Rebhan M, Nisato G, Zinggeler M, Brasier N, et al. Traditional and Digital Biomarkers: Two Worlds Apart? Digit Biomark. 2019 Aug;3(2):92-102. 